\title{
Postharvest Survey of Volatile Compounds in Five Tropical Fruits Using Headspace-solid Phase Microextraction (HS-SPME)
}

\author{
Natta Laohakunjit and Orapin Kerdchoechuen \\ School of Bioresources and Technology, King Mongkut's University of \\ Technology Thonburi, Bangkok, Thailand 10150
}

Frank B. Matta ${ }^{1}$

Department of Plant and Soil Sciences, P.O. Box 9555, Mississippi State

University, Mississippi State, MS 39762

Juan L. Silva

Department of Food Science, Nutrition and Health Promotion, P.O. Box 9805, Mississippi State University, Mississippi State, MS 39762

\section{William E. Holmes}

Mass Spectrometry and Advanced Instrumentation, Mississippi State Chemical Laboratory, P.O. Box CR, Mississippi State, MS 39762

Additional index words. Longon (Lansium domesticum), mangosteen (Garcinia mangostana), durian (Durio zibethinus), rambutan (Nephelium lappaceum), sapodilla (Manilkara zapota)

\begin{abstract}
The volatiles of longon (Lansium domesticum Corr. var Dongon), mangosteen (Garcinia mangostana L. var Native), durian (Durio zibethinus L. var Monthong), rambutan (Nephelium lappaceum L. var Rong-rien), and sapodilla (Manilkara zapota van Royer var Kai) were identified by headspace-solid phase microextraction with the gas chromatography-mass spectrometry technique. The headspace volatiles of fresh, unheated, salted out with $\mathrm{NaCl}$, and $\mathrm{NaCl}+$ heated samples were determined. Salting out gave the highest number of volatile components with the longon headspace. High temperature did not have much affect on the amount of volatiles in the headspace. Major volatiles of the total 43 volatiles in longon were 1,3,5 trioxane, (E)-2-hexenal, 3-carene, $\alpha$-cubebene, isoledene, $\delta$-selinene, and $\alpha$-calacorene. Major volatiles of mangosteen were 2, 2-dimethyl-4-octanal, E-2-hexenal, benzaldehyde, (Z)-3-hexen-1-ol, hexyl-n-valerate, 1,4-pentadiene, and 2-methyl-1, 3-buten-2-ol. Volatile compounds in durian consisted of a large number of sulfur-containing compounds, which included diethyltrisulfide, diethyldisulfide, dithiolane, dimetyl sulfide, and 3-methyl-thiozolidine. Nonsulfur compounds 2-methyl butanoate, butanedioic acid, and propyl-2-ethylbutanoate were also abundant. Isocitonellol, 3-hydroxy-2-butanone, pentanal, and 4-tridecyl valerate were most abundant in 'Rong-rien' rambutan. A total of 23 components were characterized in sapodilla with ethyl acetate, acetaldehyde, benzyl alcohol, and 2-butenyl benzene being the major volatiles.
\end{abstract}

Thailand has numerous tropical fruit that present an exotic taste and flavor. Such fruit have great economic potential as fresh or processed. Durian (Durio zibethinus L.), mangosteen (Garcinia mangostana L.), rambutan (Nephelium lappaceum L.), longon (Lansium domesticum Corr.), and sapodilla (Manilkara zapota van Royer) are native to Southeast Asia (Thailand/Malaysia/Indonesia) and require a year-round, warm, very humid,

\footnotetext{
Received for publication 21 July 2006. Accepted for publication 16 Sept. 2006.

Approved for publication by the Director of the Mississippi Agricultural and Forestry Experiment Station as Journal article J-10997.

${ }^{1}$ To whom reprint requests should be addressed; e-mailfmatta@pss.msstate.edu.
}

and equatorial climate. Durian is a member of the Bombacaceae family. One of the most praised of tropical fruits and certainly the most esteemed fruit in the Guttiferae family, mangosteen is almost universally known. Longon, a somewhat less edible fruit of the Meliaceae family, is also known as langsat, lansa, langseh, langsep, lanzon, lanzone, lansone, or kokosan and by various other names in the dialects of the Old World tropics. They are grown in the east and south of Thailand (Morton, 1987).

Native to Southeast Asia (Malaysia and Indonesia), rambutan belongs in the same family (Sapindaceae) as the subtropical fruits lychee and longan and is relatively unknown in the United States (Lam and Kosiyachinda, 1987; Macleod and Troconis, 1982; Ong et al., 1998). Sapodilla is best known as the source of chicle gum, which is the basis of chewing gum manufacturing.

Various studies on postharvest properties and marketing of these fruit have been reported with a few describing the flavor chemistry of durian, rambutan, and sapodilla (Macleod and Troconis, 1982; Weenen et al., 1996; Wong and Tie, 1995). In three varieties of Indonesian durian, 24 of the 43 peaks contributed to their flavor as analyzed by gas chromatography-mass spectrometry (GCMS). The strongest durian odorant among sulfur compounds was 3,5-dimethyl-1,2,4trithiolane and nonsulfurous odorant was ethyl 2-methylbutanoate (Baldry et al., 1972; Boelens et al., 1974; Weenen et al., 1996). Sapodilla produces a relatively small quantity of aroma volatiles (in total $\approx 5$ $\mu \mathrm{g} \cdot \mathrm{kg}^{-1}$ of fruit weight) and benzyl-related compounds comprise over $45 \%$ of the volatiles, including alkyl benzoates, methyl benzoate, methyl salicylic, and ethyl benzoate (Macleod and Troconis, 1982). The main contributors to rambutan aroma were $\beta$-damascenone, ethyl 2-methylbutarate, 2,6-nonadienal, (E)-2-nonenal, and nonanal (Ong et al., 1998).

The literature on postharvest flavor compounds or the composition of volatiles of tropical fruit longon, mangosteen, durian, rambutan, and sapodilla is limited. Volatiles were monitored by GC-MS, after various extraction methods, as simultaneous steam distillation extraction in sapodilla fruit (Macleod and Troconis, 1982), fraction distillation in durian (Weenen et al., 1996), liquid extraction in rambutan (Ong et al., 1998), hydrodistillation in African pear (Jirovetz et al., 2005), and continuous liquid-liquid extraction in pineapple fruit (Elss et al., 2005). Sample preparation such as extraction and isolation of analysis greatly influences the reliability and accuracy of flavor analysis in fruit. Present sample preparation methods for analyzing volatile compounds are liquid-liquid extraction, widely used to extract the typical aroma components, static headspace sampling, direct injection, and solid phase extraction. Most typical sample preparations for compound isolation involve steps that are time- and labor-intensive, prone to volatile loss, and often use solvents that are toxic or potential carcinogens. Furthermore, solvent extractions are generally accomplished at high temperature or under reduced pressure, which can destroy or alter some volatile flavor compounds or produce artifacts. Solid phase microextraction (SPME) is rapid, less laborious, and relatively inexpensive and does not require solvents, purge and trap, preconcentration, or vigorous extraction and heating, which may alter endogenous compounds (Pawliszyn, 1997; Zhang et al., 1994; Zhang and Pawliszyn, 1993). Also, the absorptive nature of the fibers permits assays at nondestructive temperatures. Flavor and off-flavor aromas have recently been assessed in numerous fruit and juices by SPME (Wang et al., 2004; Beaulieu and Grimm, 2001; Jia et al., 1998; Matich et al., 
1996; Song et al., 1998; Steffen and Pawliszyn, 1996). Fruit aroma is the result of a special assortment and mixture of different metabolites. The different proportions of volatile components and the presence or absence of trace components determine aromatic properties of fruit (Ayala-Zavalla et al., 2004). Flavor plays an important role in consumer satisfaction and influences further consumption of fruit (Pelayo et al., 2003). The purpose of this study was to survey the flavor compounds of tropical fruits to obtain information that may be valuable for variety improvement of tropical fruits of Thailand.

\section{Materials and Methods}

Plant materials. Durian (Durio zibethinus var. Monthong), mangosteen (Garcinia mangostana var. Native), rambutan (Nephelium lappaceum var. Rong-rien), longon (Lansium domesticum var longon), and sapodilla (Manilkara zapota var. Kai) were used in this study and grown in Eastern Thailand using good agricultural practices for horticultural crops. Mature ripe fruit were collected during Sept. 2005. Mature fruit were harvested 130, 95, 105,90 , and $110 \mathrm{~d}$ after pollination, respectively, air-cooled in the field individually wrapped with air-beaded plastic, packed carefully in cardboard boxes $(48 \mathrm{~cm} \times 72 \mathrm{~cm})$, and shipped overnight to the School of Bioresources and Technology, King Mongkut's University of Technology Thonburi, Bangkok, Thailand.

Sample preparation. Whole fruit were sanitized in $100 \mathrm{mg} \cdot \mathrm{L}^{-1}$ sodium hypochloride for 5 minutes and peeled with a knife. The fleshy pulp of durian, mangosteen, rambutan, and longon was separated from the seed. Approximately $2-$ to $3-\mathrm{cm}$ cubes were prepared from the pulp of each fruit. Sapodilla fruit were hand-peeled with a carrot peeler. All samples were prepared following the method of Beaulieu and Grimm (2001) and Beaulieu and Lea (2003). All sanitized samples, subsequent cutting procedures, and fresh-cut tissues were prepared and handled with latex gloves. Samples were prepared in duplicate, each from $250 \mathrm{~g}$ of randomly selected cubes from a representative pool of 10 mature fruit of each species. Tissue was immediately juiced into a slurry with a Braun (Braun, Boston) juicer. A 5-mL slurry (without foam) was then pipetted into $10-\mathrm{mL}$ glass vials containing $1.1 \mathrm{~g} \mathrm{NaCl}$ and blended for 2 min in a Waring blender (Waring, Atlanta) to inactivate enzymes (salted). Another 5-mL slurry of the flesh was added with liquid nitrogen (unsalted). Each sample was hermetically sealed in a $22-\mathrm{mL}$ screw-top vial with a polytetra fluoroethylene/silicone septa and kept frozen before transporting to the Plant Physiology Laboratory, Mississippi State University, Mississippi, Miss.

Heat treatment of fruit. Vials containing unsalted fruit or salted fruit were randomly equilibrated for $10 \mathrm{~min}$ at room temperature of $16{ }^{\circ} \mathrm{C}$ as nonheated samples. Heated samples were held in a thermostatic bath at $50{ }^{\circ} \mathrm{C}$ for $35 \mathrm{~min}$. Unsalted, salted, non- heated, and heated samples of each fruit were prepared in duplicate.

Headspace-solid phase microextraction. Variability in analyte recovery with SPME was observed with various sampling regimes; thus, variation was minimized by saturating slurries and keeping the heating time, sample volume, and temperature constant. Vials containing unsalted and salted samples were equilibrated at nonheated condition (at room temperature) for $10 \mathrm{~min}$. Then, volatile compounds were absorbed on an automated SPME fiber $(65 \mu \mathrm{m}$, polydimethylsiloxanedivinylbenzene) (Supelco, Bellefonte, Pa.). During SPME exposure with sample vials, the headspace above the slurry was adsorbed by a 12-h SPME exposure at room temperature $\left(22{ }^{\circ} \mathrm{C} \pm 2\right)$ overnight. In a thermostatic bath of heated samples, the headspace was obtained with the same procedure of SPME mentioned in nonheated samples. The SPME was immediately inserted into the GC injector and the fiber thermally desorbed. A desorption time of $5 \mathrm{~min}$ at $250{ }^{\circ} \mathrm{C}$ was used in a splitless mode of GC-MS. The SPME fiber was constantly reconditioned for $5 \mathrm{~min}$ in the GC injector port at $250{ }^{\circ} \mathrm{C}$. Four extraction methods (unsalted plus nonheated, unsalted plus heated, salted plus nonheated, and salted plus heated) were performed on each of the fruit types and samples subjected to GC-MS analysis with two replications.

Gas chromatography-mass spectrometry analyses. SPME fibers were desorbed at $250{ }^{\circ} \mathrm{C}$ for $5 \mathrm{~min}$ in the injection port of a Varian 3400 gas chromatograph coupled to a Varian Saturn ion trap detector 2200 (Walnut Greek, Calif.). Volatile compounds were separated in a DB wax (J\&W scientific, Folsom, Calif.) fused silica capillary column of $30 \mathrm{~m} \times$ $0.25 \mathrm{~mm}$ i.d. and $0.25-\mu \mathrm{m}$ film thickness. The injector was in split mode (split ratio, 1:20 $\mathrm{v} / \mathrm{v}$ ) and subjected to a pressure of $25 \mathrm{psi}$ of ultrahigh-purity $\mathrm{He}(99.9995 \%)$ for the first minute and then set at a constant velocity of $40 \mathrm{~cm} \cdot \mathrm{s}^{-1}$ for the remainder of the GC run. The injector and detector temperatures were $250{ }^{\circ} \mathrm{C}$ and $300{ }^{\circ} \mathrm{C}$, respectively. The column temperature was set at $40^{\circ} \mathrm{C}$, held for $3 \mathrm{~min}$, then programmed to $180{ }^{\circ} \mathrm{C}$ at $8{ }^{\circ} \mathrm{C} \mathrm{min}^{-1}$, then to $250{ }^{\circ} \mathrm{C}$ at $15^{\circ} \mathrm{C} \mathrm{min}^{-1}$ and held at this temperature for $2 \mathrm{~min}$. All mass spectra were acquired in electron impact mode and chemical impact mode; the ionization voltage was $70 \mathrm{eV}$; the mass range was 40 to $350 \mathrm{~m} / \mathrm{z}$. Compound identifications were carried out by comparing the mass spectra of standard compounds found in the instrument library [U.S. National Institute of Standards and Technology (NIST)]. Data were collected with Varian Mass Spectrometry Workstation software (Varian, Walnut, Creek, Calif) (V 6.30) and searched against the NIST (v. 1.5) libraries. Compounds were preliminarily identified by library search and then the identities of most were confirmed by GC retention time (RT), MS ion spectra, authentic compounds, or a homologous series. The MS library generally delivers a high-quality hit and matching spectra for the $E, Z$ isomer on some $E, E$ and $E, Z$ isomer pairs occurring at different RTs. Some standards were not available; thus, to deduce their identity, we relied on the fact that $Z$ isomers generally elute first. All integrated responses were examined carefully, and relative recovery (integrated area count) for specified compounds, based on selected unique qualifying target ions, was presented.

\section{Results and Discussion}

Longon. By means of GC-MS (ion trap used), more than 40 volatiles and static headspace of 36 volatiles of fresh longon (original fresh pulp) were identified; 1,3,5trioxane $(33.8 \%)$, (E)-2-hexenal $(23.8 \%)$, $\alpha$-calacorene $(6.9 \%), \alpha$-cubebene $(5.4 \%)$, isoledene $(4.7 \%)$, and copaene $(4.0 \%)$ were in a high relative amount (Table 1). In the heated fresh longon, 1,3,5-trioxane was also found as the main compound $(68.3 \%)$ among 23 volatile components followed by (E)-2-hexenal $(5.1 \%), \alpha$-cubebene $(2.3 \%)$, $\alpha$-calacorene $(2.3 \%)$, hexyl ester acetic acid $(2.0 \%), \delta$-selinene $(1.9 \%)$, and limonene $(1.3 \%)$. The remaining volatiles (17) were found in a lower amount $(0.24 \%$ to $1.2 \%)$ percent relative to peak area. Methylbutyrate, fruit, and sweet description odor (Fischer et al., 1993) were found in heated fresh longon and in unheated pulp treated with salt. The presence of methylbutyrate indicated that in fresh pulp of longon subjected to high temperature, the sweet aroma of methylbutyrate was vaporized and could be detected in the mass spectrum of GC-MS. However, acetic acid and sour odor were increased in the headspace of heated fresh longon suggesting that heat used to increase extraction rate stopped the metabolic activity or enhanced the release of analytes.

Although the relative peak of salted $(\mathrm{NaCl})$ and salted and heated longon comprised the total similar pattern and peak numbers of 35 and 23 volatiles, respectively, the main components were different. In longon subjected to $\mathrm{NaCl}$ without heating, the major constituents were $\delta$-selinene $(17.7 \%)$, isoledene $(13.9 \%), \alpha$-cubebene $(12.5 \%), \alpha$-calacorene $(10.8 \%)$, and epizoarene $(9.9 \%)$. Epizoarene was not found in salted, heated samples, but the four main components like in $\mathrm{NaCl}$ longon (isoledene, $\alpha$-cubebene, $\delta$-selinene, and $\alpha$-calacorene) were identified at $16.9 \%, 15.8 \%, 14.6 \%$, and $10.8 \%$ relative amount, respectively.

The total percent relative amount of volatiles found in $\mathrm{NaCl}$-salted longon was highest followed by normal fresh, fresh + heated, and $\mathrm{NaCl}+$ heated, respectively (Fig. 1), as indicated by the first 15-min retention time of GC-MS chromatography. At a retention time of 15 to $20 \mathrm{~min}$, the chromatogram of $\mathrm{NaCl}$ longon showed the highest peaks. Such peaks should be considered in future studies as a result of many new volatiles of longon arising during $\mathrm{NaCl}$ extraction with GC-MS analysis. Among the 45 total volatiles, acetic acid (sour aroma), (E)-2-hexenal (green, leaf aroma), limonene (citrus, lemon, 
Table 1. Headspace solid phase microextraction volatile components of longon fruit as affected by $\mathrm{NaCl}$ and heat. ${ }^{z}$

\begin{tabular}{|c|c|c|c|c|}
\hline \multirow[b]{3}{*}{ Components } & \multicolumn{2}{|c|}{ Fresh } & \multicolumn{2}{|c|}{ Salted } \\
\hline & Unheated & Heated & Unheated & $\overline{\text { Heated }}$ \\
\hline & \multicolumn{4}{|c|}{ Percent relative peak area } \\
\hline 1,3,5 Trioxane & 33.81 & 68.34 & 0.17 & \\
\hline E-2-hexenal & 23.89 & 5.14 & 2.01 & 4.96 \\
\hline Alpha-calacorene & 6.97 & 2.37 & 10.80 & 10.85 \\
\hline Alpha-cubebene & 5.48 & 2.39 & 12.53 & 15.81 \\
\hline Isoledene & 4.70 & 1.12 & 13.97 & 16.97 \\
\hline Copaene & 4.06 & 0.89 & 0.16 & \\
\hline Aromadendrene & 3.85 & 0.29 & 9.08 & 5.33 \\
\hline Delta-selinene & 3.68 & 1.98 & 17.74 & 14.62 \\
\hline Limonene & 2.01 & 1.36 & 1.17 & 2.65 \\
\hline Hexyl ester acetic acid & 1.88 & 2.03 & 0.36 & \\
\hline Phenyl ester acetic acid & 1.82 & 1.29 & 0.90 & 1.60 \\
\hline Epizoarene & 1.64 & & 9.93 & \\
\hline Beta-panasinsene & 1.22 & 0.59 & 1.64 & 5.28 \\
\hline 3-Carene & 1.17 & 0.95 & 0.38 & 0.94 \\
\hline Alpha-cadinol & 0.57 & 0.25 & 3.69 & 1.14 \\
\hline Alpha elemene & 0.54 & & 1.89 & 1.32 \\
\hline Unknown & 0.41 & 0.86 & 0.05 & 0.40 \\
\hline 1-Methoxy-2-propanol & 0.39 & 0.96 & & 0.83 \\
\hline Acetic acid & 0.39 & 6.37 & 0.21 & 0.81 \\
\hline Caryophyllene & 0.38 & & 0.91 & \\
\hline 2-Phenylethyl ester acetic acid & 0.35 & & & \\
\hline Phenylethyl alcohol & 0.34 & & & \\
\hline (Z)-3-octene & 0.32 & 0.61 & & \\
\hline Acetaldehyde & 0.26 & & & \\
\hline Metroprene & 0.21 & & 0.15 & \\
\hline 1-Methylethyl ester acetic acid & 0.18 & & & \\
\hline 4-Oxo-pentanoic acid & 0.17 & & & \\
\hline Isocaryophyllene & 0.16 & & 0.35 & 0.32 \\
\hline 2-Chloroaniline - sulfonic acid & 0.14 & & 0.44 & \\
\hline 3-Methylacetate-1-butanol & 0.13 & & & \\
\hline Benzaldehyde & 0.13 & & & \\
\hline Ocimene & 0.13 & & 0.08 & 0.37 \\
\hline Nonanal & 0.11 & 0.78 & 0.11 & \\
\hline Humulene & 0.09 & & 0.13 & \\
\hline Linalool & 0.05 & & 0.26 & 0.93 \\
\hline Unknown & & 0.24 & 0.32 & 0.48 \\
\hline 3-Hepten-1-ol & & & 0.31 & 0.58 \\
\hline Methylbutarate & & 0.52 & 0.22 & \\
\hline 2-Ethyl-1-hexanethiol & & & 0.15 & \\
\hline Octanal & & & 0.27 & 0.44 \\
\hline Alpha-pinene & & 0.30 & & \\
\hline Ylangene & & & 5.44 & 7.84 \\
\hline Alpha-muurolene & & 0.61 & 0.07 & 4.60 \\
\hline Aristolene & & & 5.80 & \\
\hline
\end{tabular}

${ }^{\mathrm{z} B l a n k s}$ indicate compounds not detected.

orange aroma), 3-carene (green, lemon aroma), $\alpha$-cubebene (citrus, fruit aroma), aromadendrene (wood aroma), isoledene (wood aroma), $\delta$-selinene (herb aroma), $\beta$ panasinsene, $\alpha$-calacorene (wood aroma), and $\alpha$-cadinol (herb, wood aroma) were found in all four longon fruit samples (Table 1). These 11 volatiles might be typical of the exotic flavor of longon. No research has characterized the flavor of longon after harvesting.

Mangosteen. Flavor volatiles of mangosteen are shown in Table 2. Twenty-nine compounds were derived from the headspace (HS)-SPME, and 19, 8, 17, and 6 volatile components were found in fresh, heated fresh, $\mathrm{NaCl}$, and $\mathrm{NaCl}+$ heated mangosteen samples, respectively. Major components found in the fresh samples were 2, 2-dimethyl-4-octanal $(36.0 \%)$, E-2-hexenal (19.2\%), benzaldehyde (12.4\%), (Z)-3hexen-1-ol (7.0\%), and hexyl-n-valerate $(5.49 \%)$. Volatiles such as 2-ethyl furan, cis 2-methyl cyclohexanal, bendazol, cyclohexyl 4-ethylbenzoate (flower, honey aroma), hexyl acetate (fruit, herb aroma), tran-3-carene-2-ol, methoprene, copaene, $\alpha$-caryophyllene (woody, floral, fragrant, sickly sweet, fresh green flavors), and $\alpha$-muurolene (wood aroma) were found in small amounts (less than $1.2 \%$ of total relative peak area). Qualitatively, however, the mangosteen in this study showed a wide range of variation in their relative amount of volatiles. The following were found in heated fresh fruit samples: (E)-2-hexenal $(30.3 \%), 1,4$-pentadiene (20.8\%), 2-methyl-1,3-buten-2-ol (10.7\%), (Z)-3-hexen-1-ol (9.5\%), benzaldehyde $(6.7 \%)$, and hexyl-n-valerate (4.2\%). Volatiles of the fresh pulp were found in greater number compared with heated fresh pulp (Fig. 1).

When fresh pulp of mangosteen was subjected to $\mathrm{NaCl}$, it was found that the amount of volatiles decreased dramatically. The volatiles, however, in the $\mathrm{NaCl}$ samples were (Z)-3-hexen-1-ol (25.5\%), E-2-hexenal
(16.9\%), 2-methyl-3-buten-2-ol (9.7\%), benzaldehyde $(8.4 \%)$, and 2 -methyl1,3-butadiene $(7.7 \%)$. Volatiles found in a small amount (less than $3.23 \%$ ) were 1,3-pentadiene, 2-ethyl furan, bendazol, 2cyclopentene-1-unecanoate, hexyl-n-valerate, copaene, $\delta$-selinene, $\alpha$-caryophllene, and $\alpha$-muurolene. The heated $\mathrm{NaCl}$ samples showed a dramatic decrease in the total number of the volatiles. Volatiles 2,2,dimethyl-4-octanal, (E)-2-hexenal, benzaldehyde, and hexyl-n-valearte were found in the amounts of $54.6 \%, 19.2 \%, 6.0 \%$, and $5.0 \%$ relative area, respectively. Volatiles (E)-2hexenal (green, leaf aroma), benzaldehyde (almond, burnt sugar aroma), and hexyl-nvalerate (sweet aroma) were in all mangosteen samples. These three volatiles might be present as mangosteen volatiles from Thailand. No report of volatiles of this fruit was found in the literature. Results may be useful for the improvement of mangosteen quality. In this study, we also found unknown volatile compounds not previously reported in the literature in higher relative amount in headspace of all mangosteen. Such volatiles were not identified and might be the acid compounds (Morton, 1987). Fresh mangosteen had a high amount of volatiles compared with $\mathrm{NaCl}$, heated fresh, and heated $\mathrm{NaCl}$ mangosteen (Fig. 1).

Durian. As expected, the volatile compounds consisted of a large number of sulfur-containing compounds (Table 3 ). The volatiles in fresh durian differed from the heated fresh, $\mathrm{NaCl}$ and $\mathrm{NaCl}+$ heated durian. The total volatile constituents found in durian samples were 43 and 24, 15, 19, and 18 in fresh, heated fresh, $\mathrm{NaCl}$ (salted), and $\mathrm{NaCl}+$ heated samples, respectively. In fresh durian, diethyltrisulfide (sulfur, cabbage aroma) was found most abundance at $44.4 \%$ relative area. Other sulfur-containing compounds were diethyldisulfide $(11.7 \%)$, dithiolane $(5.4 \%)$, dimetyl sulfide (3.3\%), L-5 propylthiomethyl hydantoin $(2.5 \%), 2,3$-butanedithiol $(2.9 \%)$, 3-chloro-benzothiophene $(2.0 \%)$, ethyl-1methylethyl disulfide $(1.4 \%)$, and carbamodithioic acid $(1.3 \%)$. In this study, a few nonsulfur compounds were identified as chloropropenoate $(6.3 \%)$, 3-hydroxy undecanoate $(1.9 \%)$ and propyl-2-ethylbutanoate, 2-methyl butanoate, hexanoic acid, and octanoate with less relative amount of the total volatiles in fresh durian. Although the heated fresh durian contained fewer compounds than the fresh samples, diethyltrisulfide $(30.2 \%)$ was highest. Dimethyldisulfide, 2-hydroxyethyl propyl sulfide dimethyl sulfide, 3-methyl-thiozolidine, dithiolane, and methyl hydrogen disulfide were also found in the sulfur-containing volatiles of heated durian at $23.9 \%, 9.9 \%, 8.4 \%, 3.9 \%, 3.1 \%$, and $2.3 \%$ relative area. Nonsulfur compounds in heated fresh durian were propyl2-ethylbutanoate $(0.8 \%)$, hexanoic acid $(2.5 \%)$, pentanoic acid $(0.5 \%)$, hexyl isovalerate $(1.9 \%)$, 3-hydroxy undecanoate $(0.5 \%)$, and propane $(1.2 \%)$. In durian samples subjected to $\mathrm{NaCl}$, the major volatile compounds were different from the fresh samples. 


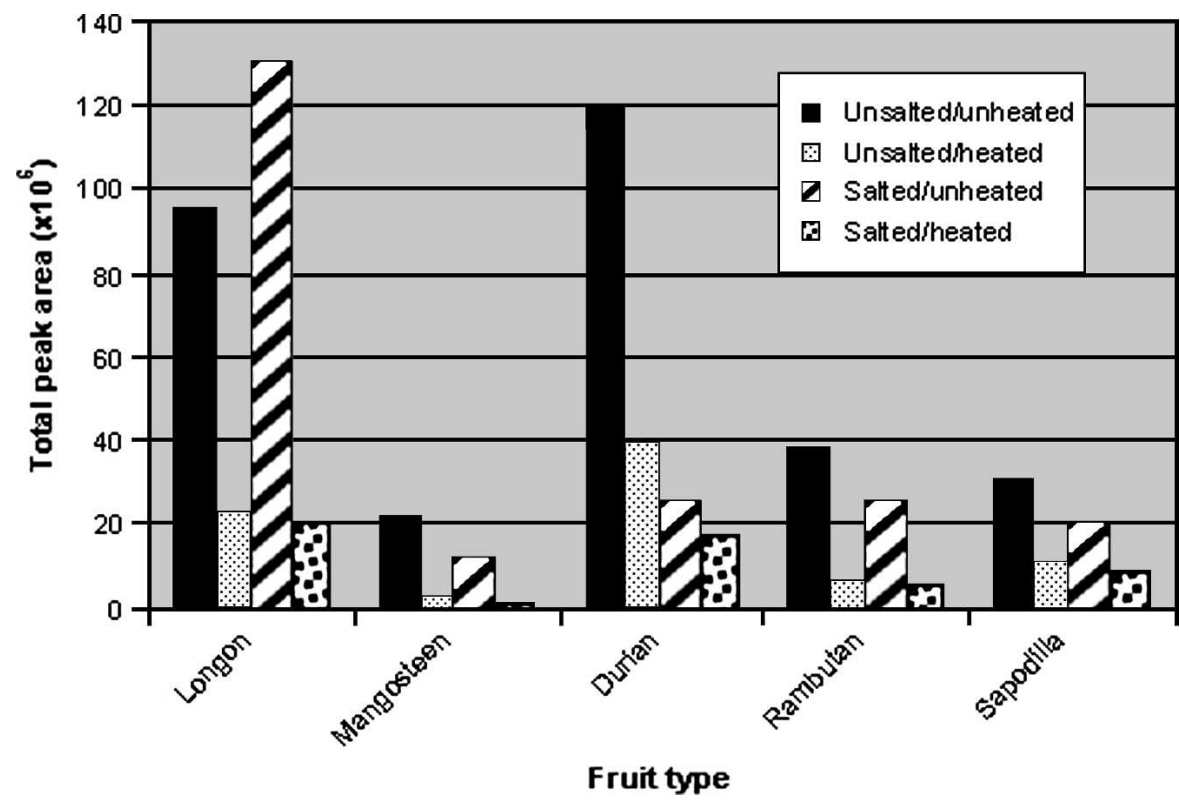

Fig. 1. Total relative area of the volatile compounds obtained from unsalted, unheated, and heated and salted unheated and heated samples of longon, mangosteen, durian, rambutan, and sapodilla from Thailand.

Table 2. Headspace solid phase microextraction volatile components of mangosteen fruit as affected by $\mathrm{NaCl}$ and heat. ${ }^{\mathrm{z}}$

\begin{tabular}{|c|c|c|c|c|}
\hline & \multicolumn{2}{|c|}{ Fresh } & \multicolumn{2}{|c|}{ Salted } \\
\hline & Unheated & $\overline{\text { Heated }}$ & Unheated & $\overline{\text { Heated }}$ \\
\hline & \multicolumn{4}{|c|}{ Percent relative peak area } \\
\hline 2,2-Dimethyl-4-octanal & 36.06 & & & 54.60 \\
\hline (E)2-hexenal & 19.25 & 30.39 & 16.94 & 19.25 \\
\hline Benzaldehyde & 12.49 & 6.72 & 8.41 & 6.02 \\
\hline Unknown & 11.68 & 11.35 & 14.42 & \\
\hline (Z)-3-hexen-1-ol & 7.00 & 9.54 & 25.50 & \\
\hline Hexyl-n-valerate & 5.49 & 4.23 & 3.23 & 5.04 \\
\hline Tran-3-caren-2-ol & 1.25 & & & \\
\hline Cis 2-methyl cyclohexanal & 1.08 & & & \\
\hline 2-Ethyl furan & 0.98 & & 0.44 & \\
\hline Alpha caryophyllene & 0.85 & & 1.44 & \\
\hline Bendazol & 0.76 & & 3.10 & \\
\hline Hexyl acetate & 0.65 & & & \\
\hline Alpha muurolene & 0.58 & & 0.53 & \\
\hline Methoprene & 0.43 & & & \\
\hline 1-Methyl-4-(1-methylethyl)-benzene & 0.42 & & & \\
\hline Copaene & 0.36 & & 1.83 & \\
\hline Unknown & 0.25 & & 0.93 & \\
\hline Unknown & 0.25 & & & \\
\hline Cyclohexyl 4-ethylbenzoate & 0.23 & & & \\
\hline Unknown & & & & 9.61 \\
\hline 1,4-Pentadiene & & 20.86 & & \\
\hline 2-Methyl-1,3-butadiene & & & 7.75 & \\
\hline 1,3-Pentadiene & & & 0.57 & \\
\hline 2-Methyl-3-buten-2-ol & & 10.70 & 9.76 & \\
\hline Unknown & & 6.21 & & \\
\hline 2-Cyclopentene-1-unecanoate & & & 2.04 & \\
\hline Anisaldehyde dimethyl acetal & & & 4.68 & \\
\hline d-Selinene & & & 0.43 & \\
\hline Unknown & & & & 5.19 \\
\hline
\end{tabular}

${ }^{\mathrm{z} B l a n k s}$ indicate compounds not detected.

Although 3-methyl-thiozolidine (28.8\%) was highest in $\mathrm{NaCl}$, 2-methyl butanoate (38.1\%) was the most abundant compound in $\mathrm{NaCl}+$ heated durian. It was found that sulfur volatile compounds (except 3-methyl-thiozolidine) in $\mathrm{NaCl}$ and $\mathrm{NaCl}+$ heated samples were less in number and total relative area, and these were dimethylsuilfide, 2-hydroxyethyl propyl sul- fide, L-5-propylthiomethyl hydantoin, diethyldisulfide, diethydisulfide butanoate, ethyl 1methylethyl disulfide, and diethyltrisulfide. These sulfur-containing compounds might be suppressed by salting in or salting out and could enhance the polarity of compounds or affect the $\mathrm{pH}$ of the samples (Pawliszyn, 1997). Therefore, the nonsulfur volatile com- pounds such as 1-methoxy-2-popanol, 2,2dimehyloxypropionamide, 3-methyl-1-butanol, 3-hydroxy ethyl hexanoate, propanoic acid, pentanoic acid, hexyl isovalerate, 3hydroxy undecanoate, hexanoic acid, butanedioic acid, and octanoic acid (rancid, fat aroma) were found in salting durian. When durian was heated, the total relative amount of volatiles decreased and the salted durian released a less amount of the total area (Fig. 1). The number of nonsulfur-containing volatiles rose as the sample was salted with $\mathrm{NaCl}$. In this study, fatty acids such as linoleic and linolenic acids were not found in the fresh and $\mathrm{NaCl}$ durian with or without heating the samples. This finding is in agreement with the report of Weenen et al. (1996) working with durian var 'Cane', although they found these two fatty acids in 'Kocak' and 'Boboko'. The three major sulfur compounds in the present study, diethyltrisulfide, 3-methyl-thiozalidine, and diethyldisulfide, were different from previous reports of Wong and Tie (1995) and Weenen et al. (1996) who reported that S-ethyl thioacetate was the major volatile in durian. This disagreement might be the result of variety, cultivation practices, and climatic conditions. Although 3,5-dimethyl-1,2,4 trithiolane was reported as the strongest durian odorant and 2-methybutanoate had the highest odor impact among the nonsulfur volatiles in durian (Weenen et al., 1996; Wong and Tie, 1995), diethyltrisulfide, diethyldisulfide, and 3-methyl-thiozolidine may contribute the strongest sulfur flavor in 'Monthong' durian. The compounds 2-methyl butanoate, butanedioic acid, and propyl-2-ethylbutanoate might be considered as having a high odor impact among nonsulfur volatiles in durian as mentioned in previous reports.

Rambutan. Compounds identified in rambutan are shown in Table 4 and Figure 1. There were 26 identified compounds and there were $19,14,21$, and 16 compounds in fresh, heated fresh, $\mathrm{NaCl}$, and $\mathrm{NaCl}+$ heated rambutan samples, respectively. In fresh rambutan analysis, isocitronellol (29.88\%), 3-hydroxy -2-butanone (14.25\%), 1-propane1-thiol (12.53\%), 4-tridecyl valerate $(6.37 \%)$, 3-methyl-2-hexanal $(6.20 \%)$, pentanal $(4.43 \%)$, decene $(3.62 \%), \delta$-decalactone $(3.37 \%)$, and benzaldehyde $(3.34 \%)$ were the major contributions in the volatiles of fresh rambutan. In heated samples, the volatiles were different and the major compounds were 3-hydroxy 2-butanone (23.24\%), isocitronelle (22.22\%), 1-propane-1-thiol $(16.56 \%)$, pentyl acetate $(14.73 \%)$, 4-tridecyl valerate $(7.57 \%)$, and pentanal $(5.16 \%)$. In the $\mathrm{NaCl}$ and $\mathrm{NaCl}+$ heated rambutan, the major constituents were isocitronellol, 4-tridecyl valerate, pentanal, 3-hydroxy-2butanone, and benzaldehyde. Results showed that isocitronellol (floral, intense rose like, weak fruit aroma), 3-hydroxy-2-butanone, pentanal, and 4-tridecyl valerate attributed to the odor of rambutan, although $\mathrm{NaCl}$ and high temperature affected the relative amount of these four compounds. Temperature and $\mathrm{pH}$ were the important extraction 
Table 3. Headspace solid phase microextraction volatile components of durian fruit as affected by $\mathrm{NaCl}$ and heating condition. ${ }^{2}$

\begin{tabular}{|c|c|c|c|c|}
\hline \multirow[b]{3}{*}{ Components } & \multicolumn{2}{|c|}{ Fresh } & \multicolumn{2}{|c|}{ Salted } \\
\hline & Unheated & Heated & Unheated & $\overline{\text { Heated }}$ \\
\hline & \multicolumn{4}{|c|}{ Percent relative peak area } \\
\hline Diethyltrisulfide & 44.47 & 30.23 & 3.20 & 0.80 \\
\hline Diethyldisulfide & 11.73 & 23.92 & 5.06 & \\
\hline Chloropropenoate & 6.36 & & & \\
\hline Dithiolane & 5.44 & 3.10 & & \\
\hline Unknown & 5.32 & & & \\
\hline Dimethyl sulfide & 3.32 & 8.44 & 1.06 & 1.18 \\
\hline 2,3-Butanedithiol & 2.93 & 5.01 & & \\
\hline L-5 Propylthiomethyl hydantoin & 2.57 & 9.94 & 4.82 & 1.28 \\
\hline 3-Chloro-benzothiophene & 2.07 & & & \\
\hline 3-Hydroxy undecanoate & 1.92 & 0.59 & & 0.73 \\
\hline 4-Chlorophenylamino-butan-2-one & 1.61 & & & \\
\hline Ethyl 1-methylethyl disulfide & 1.47 & 1.70 & & 0.74 \\
\hline Ethane & 1.47 & & & \\
\hline Carbamodithioic acid & 1.31 & & & \\
\hline 3-Hydroxymandelic acid & 1.31 & & 1.41 & \\
\hline 1,1 -Bis (ethylthio)-ethane & 1.18 & & & \\
\hline Dimethoxyphenyl-1H-indole & 0.99 & & 1.41 & \\
\hline 3-Methyl-thiozolidine & 0.91 & 3.95 & 28.87 & 17.46 \\
\hline Methyl ethyl disulfide & 0.76 & 1.47 & & \\
\hline Octanoate & 0.64 & & & \\
\hline 2-Methyl butanoate & 0.62 & 2.55 & 14.80 & 38.12 \\
\hline Hexanoic acid & 0.58 & & & 5.52 \\
\hline 2-(Methoxymethoxy)-propanoic acid & 0.47 & & & \\
\hline Propyl-2-ethylbutanoate & 0.46 & 0.89 & & \\
\hline Unknown & 0.43 & 0.85 & & \\
\hline Methyl hydrogen disulfide & & 2.32 & & \\
\hline 1-Methoxy-2-propanol & & & 7.25 & 5.77 \\
\hline 2-Hydroxyethyl propyl sulfide & & & & 2.55 \\
\hline 2,2-Dimethoxypropionamide & & & & 8.38 \\
\hline 3-Methyl-1-butanol & & & 1.62 & \\
\hline 3-Mercaptohexy butanoate & & & 1.04 & 2.51 \\
\hline S-Ethyl-ethanethionate & & 1.23 & & \\
\hline 3-Hydroxy ethyl hexanoate & & & & 6.72 \\
\hline Propyl-2-ethylbutanoate & & & 9.08 & \\
\hline Propyl propanoate & & & & 1.39 \\
\hline Propanoic acid & & & 1.42 & \\
\hline Pentanoic acid & & 0.57 & 1.01 & 0.66 \\
\hline Diethyldisulfide butanoate & & & & 0.74 \\
\hline Hexyl isovalerate & & 1.90 & 2.95 & 3.83 \\
\hline Butanedioic acid & & & 10.95 & 0.65 \\
\hline Propane & & 1.28 & 1.24 & \\
\hline Ethylcyclohexanepropinoate & & & 1.08 & \\
\hline Octanoic acid & & & 1.75 & \\
\hline
\end{tabular}

${ }^{2}$ Blanks indicate compounds not detected.

parameters, having a strong positive influence. Temperature can influence the partitioning of the sample and headspace compounds as well as the change in vapor pressure of the compounds in the samples (Pellati et al., 2005). As previously reported by Ong et al. (1998), $\beta$-damascenone (fruity floral aroma), ethyl-2-methylbutarate, 2,6-nonadienal, (E)-2-nonenal, and nonenal were the main contributors in the fruit of 'Jitlee' rambutan, but we found isocitonellol, 3-hydroxy-2butanone, pentanal, and 4-tridecyl valerate were the most abundant in 'Rong-rien' rambutan from Thailand. Such differences might be the result of a difference in analysis technique, cultivar, and cultural practices.

Sapodilla. The compounds identified in sapodilla are listed in Table 5. A total of 23 compounds were characterized. Ethyl acetate $(29.30 \%)$, acetaldehyde $(21.62 \%)$, benzyl alcohol (11.93\%), and 2-butenyl benzene $(7.37 \%)$ were the major compounds in fresh samples and acetaldehyde (49.22\%) and area compared with fresh unsalted samples. $\mathrm{NaCl}$ was added to homogenized slurries as a "salting out" technique used for maximizing volatile partitioning onto the headspace phase over the liquid phase during equilibration and SPME absorption (Beaulieu and Lea, 2003). For fresh fruit samples, fresh durian showed the strongest aroma compared with the heated fresh, $\mathrm{NaCl}$, and $\mathrm{NaCl}+$ heated durian. Fruit of mangosteen, rambutan, and sapodilla showed a similar pattern or highest volatiles in fresh than in $\mathrm{NaCl}$, heated fresh, and $\mathrm{NaCl}+$ heated samples. These results are not in agreement with Singh et al. (2004) who stated that high temperature increased the production of aromatic volatile compounds.

In summary, HS-SPME might be useful in identifying the flavor compounds in addition to the strongest aroma flavor compounds of durian, the alcoholic flavor compounds of sapodilla, the sweet flavor compounds of rambutan, and the acidic flavor compounds of mangosteen. Heated temperature of HSSPME was not useful for the tropical fruits used in this study.

In addition, the major volatiles of the total 45 volatiles in longon were 1,3,5 trioxane, (E)-2-hexeal, 3-carene, $\alpha$-cubebene, isoledene, $\delta$-selinene, and $\alpha$-calacorene. The major components of mangosteen were 2 , 2-dimethyl-4-octanal, E-2-hexenal, benzaldehyde, (Z)-3-hexen-1-ol, hexyl -n-valerate, 1,4-pentadiene, and 2-methyl-1,3-buten-2-ol. The volatile compounds in fresh durian consisted of a large number of sulfur-containing compounds; diethyltrisulfide, diethyldisulfide, dithiolane, dimetyl sulfide, and 3methyl-thiozolidine were found the highest in $\mathrm{NaCl}$ samples. The compound 2-methyl butanoate was the most abundant compound in $\mathrm{NaCl}+$ heated durian and diethyltrisulfide, diethyldisulfide, and 3-methyl-thiozolidine might contribute as the strongest sulfur volatile flavor compounds in 'Monthong' durian. The compounds 2-methyl butanoate, butanedioic acid, and propyl-2-ethylbutanoate might be considered as odor imparting among nonsulfur volatiles in durian as mentioned in previous reports. In rambutan, isocitonellol, 3-hydroxy-2-butanone, pentanal, and 4tridecyl valerate were found most abundant in 'Rong-rien' rambutan from Thailand. A total of 23 components were characterized and ethyl acetate, acetaldehyde, benzyl alcohol, and 2-butenyl benzene were the major components in fresh samples of sapodilla; and acetaldehyde and methyl acetate were the main compounds in heated fresh sapodilla. These volatile compounds will be important for further improvement of the aromatic quality of tropical fruit for the consumer outside the Southeast Asian countries who are not familiar with the typical, exotic, and strong aromatic flavor of such fruit. These results may be useful in improving the organoleptic and flavor quality of fruit after harvested fruit. Furthermore, gas chromatography-olfactometry may be correlated to the HS-SPMEGC-MS technique for describing the volatile compounds in these fruit. 
Table 4. Headspace solid phase microextraction volatile components of rambutan fruit as affected by $\mathrm{NaCl}$ and heat. ${ }^{\mathrm{z}}$

\begin{tabular}{|c|c|c|c|c|}
\hline \multirow[b]{3}{*}{ Components } & \multicolumn{2}{|c|}{ Fresh } & \multicolumn{2}{|c|}{ Salted } \\
\hline & Unheated & Heated & Unheated & Heated \\
\hline & \multicolumn{4}{|c|}{ Percent relative peak area } \\
\hline Isocitronellol & 29.88 & 22.22 & 21.27 & 31.94 \\
\hline 3-Hydroxy 2 butanone & 14.25 & 23.24 & 10.92 & 8.15 \\
\hline 1-Propene-1-thiol & 12.53 & 16.56 & 1.47 & 1.81 \\
\hline 4-Tridecyl valerate & 6.37 & 7.57 & 17.80 & 16.67 \\
\hline 3-Methyl-2-hexanal & 6.20 & 1.07 & & \\
\hline Pentanal & 4.43 & 5.16 & 15.36 & 4.34 \\
\hline Unknown & 3.93 & & 7.94 & 5.44 \\
\hline Unknown & 3.65 & 1.40 & 0.44 & \\
\hline Decene & 3.62 & & 2.79 & 2.20 \\
\hline Delta-decalactone & 3.37 & 1.56 & & \\
\hline Benzaldehyde & 3.34 & & 5.85 & 6.04 \\
\hline Acetaldehyde & 2.55 & & & \\
\hline Unknown & 2.42 & 1.31 & 4.05 & 8.41 \\
\hline Pentyl acetate & 1.54 & 14.73 & 2.53 & 1.29 \\
\hline E,E-2,4-Hexadienal & 0.78 & 1.23 & 0.58 & 1.72 \\
\hline Acetate & 0.78 & & & 6.11 \\
\hline Hexanal & 0.54 & & 3.57 & \\
\hline Pentanoic acid/ Hexanoic acid & 0.43 & & 1.00 & \\
\hline 2,5,6-Trimethyldecene & 0.38 & & & \\
\hline 2-Propyl-1-pentanal & & 1.11 & 1.28 & 1.69 \\
\hline 2-Hydroxy propanoic acid/4-penten-2-ol & & 2.83 & 0.56 & \\
\hline 2-Butanoate & & & 0.45 & \\
\hline Heptanol & & & 0.59 & 1.53 \\
\hline 1-Nonen-3-ol & & & 1.08 & 1.46 \\
\hline Hexadecanoic acid & & & 1.54 & \\
\hline Nonanal & & & 0.47 & 1.17 \\
\hline
\end{tabular}

${ }^{\mathrm{z} B l a n k s}$ indicate compounds not detected.

Table 5. Headspace solid phase microextraction volatile components of sapodilla fruit as affected by $\mathrm{NaCl}$ and heat. ${ }^{\mathrm{z}}$

\begin{tabular}{|c|c|c|c|c|}
\hline \multirow[b]{3}{*}{ Components } & \multicolumn{2}{|c|}{ Fresh } & \multicolumn{2}{|c|}{ Salted } \\
\hline & Unheated & Heated & Unheated & Heated \\
\hline & \multicolumn{4}{|c|}{ Percent relative peak area } \\
\hline Ethyl acetate & 29.37 & 49.22 & 21.92 & 3.18 \\
\hline Acetaldehyde & 21.60 & 33.31 & 42.44 & 48.61 \\
\hline Benzyl alcohol & 11.93 & 1.05 & 10.32 & 6.71 \\
\hline Unknown & 8.97 & 0.84 & 6.78 & 5.28 \\
\hline 2-Butenyl benzene & 7.37 & 1.31 & 5.69 & \\
\hline Methyl acetate & 2.76 & 5.22 & 3.04 & 17.65 \\
\hline 3-(1-Ethoxyethoxy)-2-methyl butanal & 2.31 & & & \\
\hline Benzenediol & 2.26 & 0.54 & 0.74 & \\
\hline Dimethylhexane & 1.44 & 0.50 & 2.72 & 2.00 \\
\hline (E)-2-Hexenal & 0.58 & 0.46 & 0.65 & \\
\hline 4-Penten-2-ol & 0.29 & 0.77 & & \\
\hline 3-Carene & 0.29 & 0.55 & 0.51 & \\
\hline 2-Methyl butanoate & 0.25 & 0.95 & & \\
\hline 1-Methoxy-2 propanol & 0.23 & 0.57 & & \\
\hline Benzoyl isothiocyanoate & 0.21 & & 0.60 & \\
\hline 1-Methoxy 2-propanol & 0.18 & 1.19 & 1.00 & \\
\hline 2-Methoxy-ethanol & & & & 8.06 \\
\hline Acetic acid & & & 2.27 & \\
\hline Butylresocinol & & & & 1.83 \\
\hline Cyclopentanol & & 2.50 & & 1.21 \\
\hline 3-Ethyl-2-butanol & & 0.92 & 0.80 & \\
\hline Benzoylformic acid & & & 1.50 & \\
\hline Stearic acid & & & & 5.47 \\
\hline
\end{tabular}

${ }^{\mathrm{z}}$ Blanks indicate compounds not detected.

\section{Literature Cited}

Ayala-Zavalla, J.F., S.Y. Wang, C.Y. Wang, and G.A. Gonzalez-Aguilar. 2004. Effect of storage temperatures on antioxidant capacity and aroma compounds in strawberry fruit. LWT. 37:687-695.

Baldry, J., J. Douan, and G.E. Howard. 1972. Volatile flavoring constituents of durian. Phytochem. 11:2081-2084.

Beaulieu, J.C. and C.C. Grimm. 2001. Identification of volatile compounds in cantaloupe at various developmental stages using solid phase microextraction. J. Agr. Food Chem. 49:1345-1352. of pineapple fruit [Ananas comosus (L.) Merr.] and pineapple products. LWT. 38:263-274.

Fischer, N., F.J. Hammerschmidt, and E.J. Brunke. 1993. Analytical investigation of flavor of capuacu (Theobroma gradiflorum Spreng.), pp. 8-20. In R.L. Rouseff and M.M. Leady (eds.) Fruit flavors. ACS Symposium Series 596.

Jia, M.Y., Q.H. Zhang, and D.B. Min. 1998. Optimization of solid-phase microextraction analysis for headspace flavor compounds of orange juice. J. Agr. Food Chem. 46:2744-2747.

Jirovetz, L., G. Buchbauer, M.B. Ngassoum, and M. Parmentier. 2005. Chemical composition and olfactory characterization of essential oils of fruits and seeds of African pear (Dacryodes edulis (G. Don) H. J. Lam) from Cameroon. Flavour Fragr. J. 20:215-218.

Lam, P.F. and S. Kosiyachinda. 1987. Rambutan: Fruit development, postharvest physiology and marketing in ASEAN. ASEAN Food Handling Bureau, Kuala Lumpur, Malaysia.

Macleod, A.J. and N.G. Troconis. 1982. Volatile flavor components of sapodilla fruit (Achras sapota L.). J. Agr. Food Chem. 30:515-517.

Matich, A.J., D.D. Rowan, and H.N. Bank. 1996. Solid-phase microextraction for quantitative headspace sampling of apple volatiles. Anal. Chem. 68:4114-4118.

Morton, J.F. 1987. Fruits of warm climates. Julia F. Morton, Miami, Fla.

Moser, R., D. Duvel, and D. Greve. 1980. Volatile constituents of durian (Durio zibethinus Murr.). Phytochem. 19:79-81.

Ong, P.K.C., T.E. Acree, and E.H. Lavin. 1998. Characterization of volatiles in rambutan fruit (Nephelium lappaceum L.). J. Agr. Food Chem. 46:611-615.

Pawliszyn, J. 1997. Solid phase microextractionTheory and practice. Wiley-VCH, Chichester.

Pelayo, C., S.E. Ebeler, and A.A. Kader. 2003 Postharvest life and flavor quality of three strawberry cultivars kept at $5^{\circ} \mathrm{C}$ in air or air $+20 \mathrm{kPa}$ $\mathrm{CO}_{2}$. Postharvest Biol. Tech. 27:171-183.

Pellati, F., S. Benvenuti, F. Yoshizaki, D. Bertelli, and M.C. Rossi. 2005. Headspace solid-phase microextraction of the volatile compounds of Evodia species fruits. J Chromatogr A. 1087:256-273.

Singh, Z., H.J.D. Latel, and S. Nair. 2004. A review of mango fruit aroma volatile compounds: State of the art research. Acta Hort. 645:519-527.

Song, J., L.H. Fan, and R.M. Beaudry. 1998 Application of solid-phase microextraction and gas chromatography time of-flight mass spectrometry for rapid analysis of flavor volatiles in tomato and strawberry fruits. J. Agr. Food Chem. 46:3721-3726.

Steffen, A. and J. Pawliszyn. 1996. Analysis of flavor volatiles using headspace solid-phase microextraction. J. Agr. Food Chem. 44:2187-2193.

Wang, L., Y. Xu, G. Zhao, and J. Li. 2004. Rapid analysis of flavor volatiles in apple wine using headspace solid-phase microextraction. J. Ins. Brewing. 110:57-65.

Weenen, H., W.E. Koolhaas, and A. Apriyantono. 1996. Sulfur-containing volatiles of durian fruits (Durio zibethinus Murr.). J. Agr. Food Chem. 44:3291-3293.

Wong, K.C. and D.Y. Tie. 1995. Volatile constituents of durian (Durio zibethinus Murr.). Flavour Fragr. J. 10:79-83.

Zhang, G. and J. Pawliszyn. 1993. Headspace solid-phase microextraction. Anal. Chem. 65:1843-1852.

Zhang, G., M. Yang, and J. Pawliszyn. 1994. Solidphase microextraction: A solvent-free alternate for sample preparation. Anal. Chem. 66:844A$853 \mathrm{~A}$. 